\title{
Health benefits of a vegetarian diet
}

\author{
Timothy J. Key*, Gwyneth K. Davey and Paul N. Appleby \\ Imperial Cancer Research Fund, Cancer Epidemiology Unit, University of Oxford, Radcliffe Infirmary, Oxford OX2 6HE, UK
}

\begin{abstract}
Compared with non-vegetarians, Western vegetarians have a lower mean BMI (by about $1 \mathrm{~kg} / \mathrm{m}^{2}$ ), a lower mean plasma total cholesterol concentration (by about $0.5 \mathrm{mmol} / \mathrm{l}$ ), and a lower mortality from IHD (by about $25 \%$ ). They may also have a lower risk for some other diseases such as constipation, diverticular disease, gallstones and appendicitis. No differences in mortality from common cancers have been established. There is no evidence of adverse effects on mortality. Much more information is needed, particularly on other causes of death, other morbidity including osteoporosis, and long-term health in vegans. The evidence available suggests that widespread adoption of a vegetarian diet could prevent approximately 40000 deaths from IHD in Britain each year.
\end{abstract}

\section{Vegetarians: Vegan: Mortality: IHD: Cancer}

Vegetarian diets are based on cereals, pulses, nuts, vegetables and fruits, and may also include dairy products and eggs. Lacto-ovo-vegetarians do not consume any meat, poultry or fish, but do include dairy products and eggs in their diet; vegans do not consume any foods of animal origin. Unless otherwise specified, reference to vegetarians means lacto-ovo-vegetarians, because relatively little information is available for vegans. In general, a vegetarian diet is lower in saturated fat and higher in starch, NSP, fruits and vegetables than a non-vegetarian diet.

In the present short overview we describe first the relationships between vegetarian diets and BMI and plasma cholesterol concentrations, and then the relationships between vegetarian diets and mortality from the commonest causes of death. The present paper concentrates on major findings from studies of Caucasian Western vegetarians. More extensive reviews have been published by Dwyer (1988, 1991), Sanders \& Reddy (1994) and Thorogood (1995).

\section{BMI and obesity}

Numerous studies have consistently found that vegetarians are on average thinner than comparable non-vegetarians (Dwyer, 1988; Thorogood, 1995; Key \& Davey, 1996; Key et al. 1998). The data from four large cohorts are shown in Fig. 1. The average BMI varies substantially between cohorts (higher in the Seventh-day Adventist cohorts in California, USA (Snowdon et al. 1984; Fraser et al. 1992) than in the European cohorts (Chang-Claude et al. 1992; Thorogood et al. 1994)), but on average vegetarians in each cohort have a BMI about $1 \mathrm{~kg} / \mathrm{m}^{2}$ lower than that of nonvegetarians within the same cohort. The difference is similar in men and women, and is seen in all age-groups (Fig. 2). The lower mean BMI of vegetarians leads to a substantially lower prevalence of obesity (Fig. 3; Key \& Davey, 1996).

The reasons for this association have not been established. An analysis of data from 5000 men and women

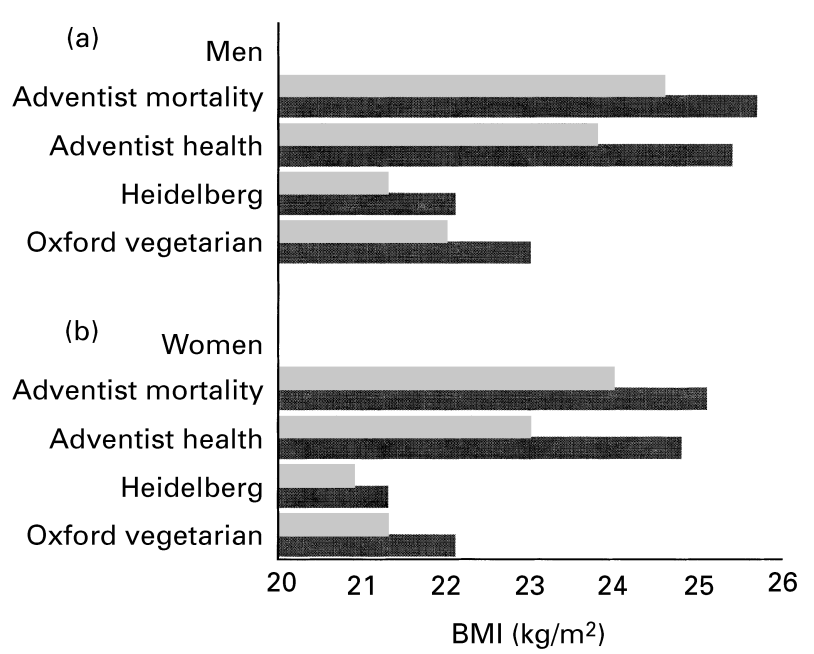

Fig. 1. Mean BMI in vegetarians $(-5)$ and non-vegetarians $(\boldsymbol{\square})$ in four large cohort studies. (Adapted from Key et al. 1998.) 


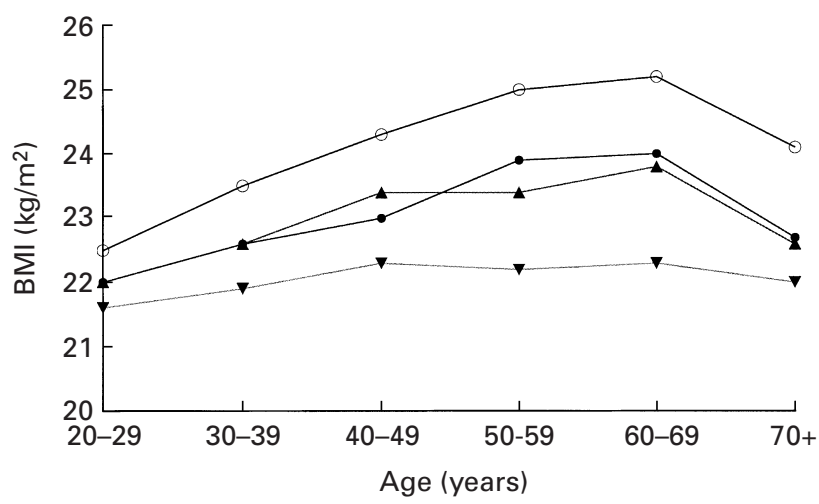

Fig. 2. BMI by age and diet group in 17158 women in the European Prospective Investigation into Cancer and Nutrition (Key \& Davey,

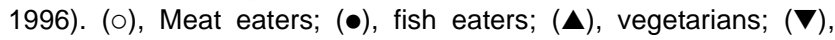
vegans.

in the Oxford Vegetarian study (Appleby et al. 1998) suggested that the lower BMI of non-meat eaters than meat eaters is partly due to a higher intake of dietary fibre and a lower intake of animal fat, and in men only, a lower intake of alcohol. These factors, however, accounted for only onethird of the difference in BMI observed.

\section{Plasma cholesterol concentration}

Studies have consistently reported that vegetarians have lower mean plasma total cholesterol concentrations than comparable non-vegetarians (Dwyer, 1988, 1991; Sanders \& Reddy, 1994; Thorogood, 1995). In an analysis of data from 3000 men and women, Thorogood et al. (1987) reported that mean total cholesterol concentrations $(\mathrm{mmol} / \mathrm{l})$, adjusted for age and sex, were 4.29 in vegans, 4.88 in vegetarians, 5.01 in fish eaters and 5.31 in meat eaters (Table 1). Mean concentrations of HDL-cholesterol were higher in the fish eaters, but otherwise did not differ between the groups.

\section{Mortality}

The relatively low plasma cholesterol concentrations of vegetarians would be expected to reduce the risk of IHD. Thorogood et al. (1987), for example, estimated that the $0.4 \mathrm{mmol} / \mathrm{l}$ lower plasma cholesterol concentration of vegetarians compared with meat eaters which they observed might lead to a $24 \%$ reduction in the incidence of IHD. It is also possible that vegetarian diets might protect against (a)

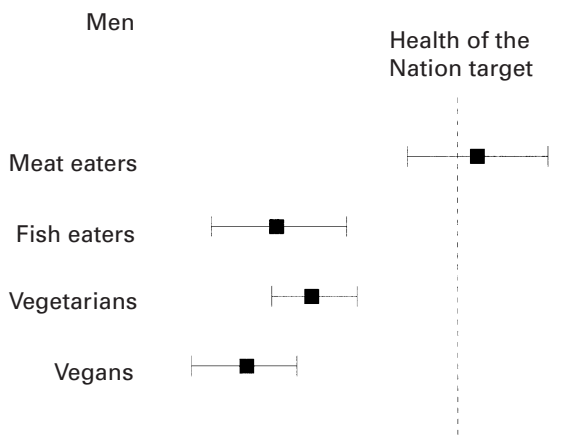

(b) Women Health of the Nation target

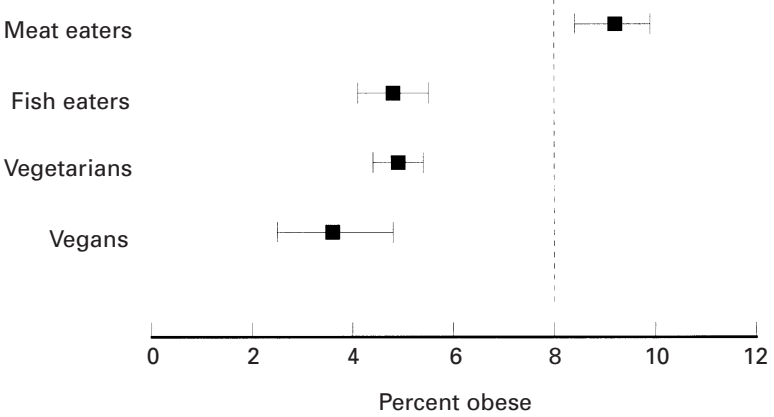

Fig. 3. Percentage of obese subjects in different dietary groups. Data for 3947 men and 17158 women in the European Prospective Investigation into Cancer and Nutrition. Health of the Nation targets are that the percentages of men and women who are obese should be reduced to 6 and 8 respectively by 2005 (Department of Health, 1992). (Adapted from Key \& Davey, 1996.)

cancers of the colo-rectum, breast and prostate, since these cancers are common in rich countries but rare in poor countries with predominantly plant-based diets.

Data on mortality rates in Western vegetarians are available from five cohort studies. Two of these studies were conducted among Seventh-day Adventists in California, USA (Snowdon et al. 1984; Fraser et al. 1992), two among members of the Vegetarian Society and other vegetarians and comparable non-vegetarians in Britain (Burr \& Butland, 1988; Thorogood et al. 1994), and one among the readers of vegetarian magazines in Germany (Chang-Claude et al. 1992). We (Key et al. 1998) have recently published a pooled analysis of original data from these five cohort studies, including data for 76000 men and women

Table 1. Plasma lipid concentrations in vegetarians and non-vegetarians, adjusted for age and sex (From Thorogood et al. 1987) (Mean values with their standard errors)

\begin{tabular}{|c|c|c|c|c|c|c|c|}
\hline \multirow[b]{2}{*}{ Diet } & \multirow[b]{2}{*}{$n$} & \multicolumn{2}{|c|}{ Total cholesterol $(\mathrm{mmol} / \mathrm{l})$} & \multicolumn{2}{|c|}{ LDL-cholesterol (mmol/l) } & \multicolumn{2}{|c|}{ HDL-cholesterol (mmol/l) } \\
\hline & & Mean & SE & Mean & SE & Mean & SE \\
\hline Vegan & 114 & $4 \cdot 29$ & 0.140 & $2 \cdot 28$ & 0.126 & $1 \cdot 49$ & 0.048 \\
\hline Vegetarian & 1550 & $4 \cdot 88$ & 0.100 & 2.74 & 0.090 & $1 \cdot 50$ & 0.035 \\
\hline Fish eater & 415 & $5 \cdot 01$ & 0.109 & $2 \cdot 88$ & 0.098 & 1.56 & 0.038 \\
\hline Meat eater & 1198 & 5.31 & $0 \cdot 101$ & $3 \cdot 17$ & 0.091 & 1.49 & 0.035 \\
\hline
\end{tabular}


among whom there were 8300 deaths before age 90 years after an average 11 years of follow up. In all these cohorts, approximately $40-50 \%$ of the subjects recruited were vegetarian and, importantly, the vegetarians and the nonvegetarians in each study had a shared interest in healthy living or a similar social and/or religious background. The results summarized below are for mortality rates among vegetarians compared with non-vegetarians. All results were adjusted for age, sex and smoking, and a randomeffects model was used to calculate pooled estimates of effect for all studies combined. Further adjustments for BMI, alcohol consumption, exercise and educational level had little effect on the results. As far as we are aware these are all the data available concerning mortality in Westernstyle vegetarians.

\section{IHD}

In the pooled analysis of cohort studies (Key et al. 1998) there were 2264 deaths from IHD before age 90 years. In comparison with non-vegetarians, vegetarians had a $24 \%$ reduction in mortality from this disease (death rate ratio 0.76 $(95 \%$ CI $0.62,0.94))$. The reduction in mortality was greater at younger ages: death rate ratios were 0.55 (95\% CI 0.35 , 0.85 ), 0.69 (95\% CI $0.53,0.90$ ) and 0.92 (95\% CI 0.73 , $1 \cdot 16$ ) for deaths from IHD at ages $<65,65-79$ and $80-89$ years respectively. The reduction in mortality was confined to vegetarians who had followed their current diet for more than 5 years. When the non-vegetarians were divided into regular meat eaters (who ate meat at least once per week) and semi-vegetarians (who ate fish only or ate meat less than once per week), the IHD death rate ratios, when compared with regular meat eaters, were $0.78(95 \%$ CI $0.68,0.89)$ in semi-vegetarians and 0.66 (95\% CI $0.53,0.83)$ in vegetarians (test for trend $P<0.001$; Fig. 4).

There is thus very strong evidence that vegetarians have a lower risk of dying from IHD than comparable nonVegetarians. There are currently about 165000 deaths from IHD each year in Britain, therefore a $24 \%$ reduction in the death rate could prevent about 40000 deaths each year in this country alone.

It is likely that the reduction in IHD among vegetarians is at least partly due to a lower dietary intake of saturated fat and cholesterol. In an analysis of data from the Oxford Vegetarian study (Mann et al. 1997), in which vegetarians had a $17 \%$ lower mortality from IHD than regular meat eaters, consumption of cheese, eggs, total animal fat and dietary cholesterol were each strongly associated with IHD mortality. Compared with those who ate relatively little of these foods, the death rate ratios in those who ate the most were $2.47(95 \%$ CI $0.97,6.26)$ for cheese, 2.68 (95\% CI $1.19,6.02)$ for eggs, 3.29 (95\% CI $1.50,7.21)$ for total animal fat and $3.53(95 \%$ CI $1.57,7.96)$ for dietary cholesterol (Fig. 5).

\section{Cancers}

The pooled analysis of five prospective studies presented mortality data for the five commonest cancers: lung, colorectal, breast, prostate and stomach (Key et al. 1998). (a)

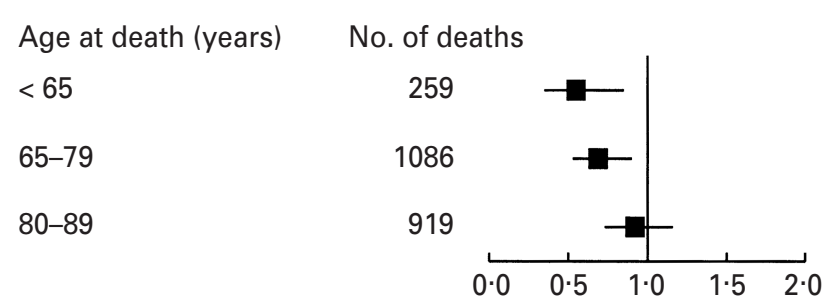

(b)

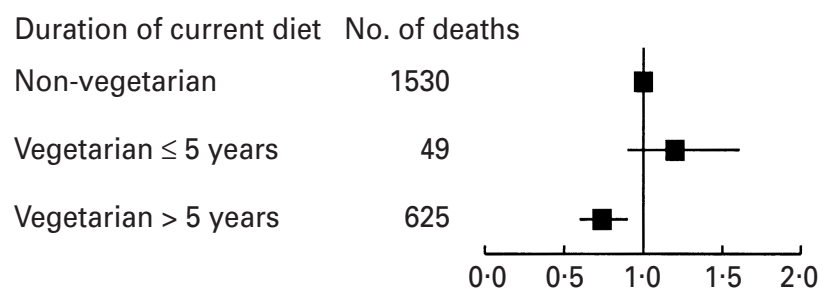

(c)

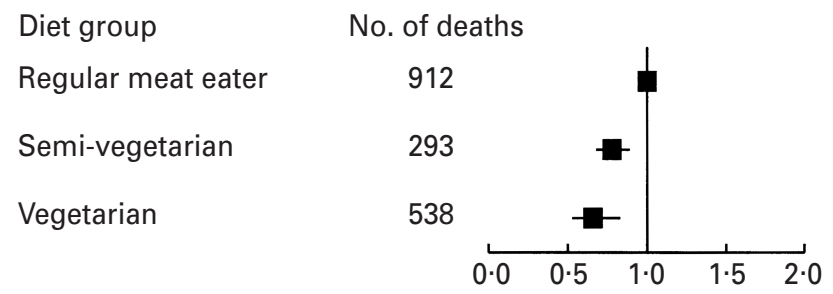

Fig. 4. Pooled analysis of mortality in vegetarians and nonvegetarians: death rate ratios for IHD by (a) age at death (vegetarians:non-vegetarians), (b) duration of current diet (vegetarians: non-vegetarians; duration unknown for some vegetarians), and (c) diet group (regular meat eater, meat eaten at least once per week; semi-vegetarian, fish but not meat eaten, or meat eaten less than once per week; vegetarian, no meat or fish eaten; expressed relative to regular meat eaters; subdivision unavailable for one study), adjusted for age, sex, and smoking, and for study using a random-effects model. Values are shown with $95 \% \mathrm{Cl}$ represented by horizontal bars. (Adapted from Key et al. 1998.)

Mortality among the vegetarians did not differ significantly from that of the non-vegetarians for any of these cancer sites. Mortality from colo-rectal cancer, for which the hypothesis that vegetarian diets might reduce risk was considered to be strongest, was almost identical in vegetarians and non-vegetarians (death rate ratio 0.99 (95\% CI $0.77,1.27)$ ), and this did not vary according to age at death or according to the length of time for which vegetarians had followed their current diet.

\section{Other causes of death and all-cause mortality}

The pooled analysis of five prospective studies presented mortality data for cerebrovascular disease (Key et al. 1998). The death rate ratio in vegetarians compared with nonvegetarians was 0.93 (95\% CI $0.74,1 \cdot 17$ ). No other individual causes of death were examined because numbers of subjects were small. All-cause mortality was $5 \%$ lower in 


\begin{tabular}{|c|c|}
\hline Dietary factor & Group \\
\hline $\begin{array}{l}\text { Cheese } \\
\text { (excluding cottage) }\end{array}$ & $\begin{array}{l}<\text { Once per week } \\
\text { One to four times per weel } \\
\geq \text { Five times per week }\end{array}$ \\
\hline Eggs (per week) & $\begin{array}{l}<1 \\
1-5 \\
6+\end{array}$ \\
\hline Total animal fat & $\begin{array}{l}\text { 1st tertile (lowest) } \\
\text { 2nd tertile } \\
\text { 3rd tertile }\end{array}$ \\
\hline Dietary cholesterol & $\begin{array}{l}\text { 1st tertile (lowest) } \\
\text { 2nd tertile } \\
\text { 3rd tertile }\end{array}$ \\
\hline
\end{tabular}

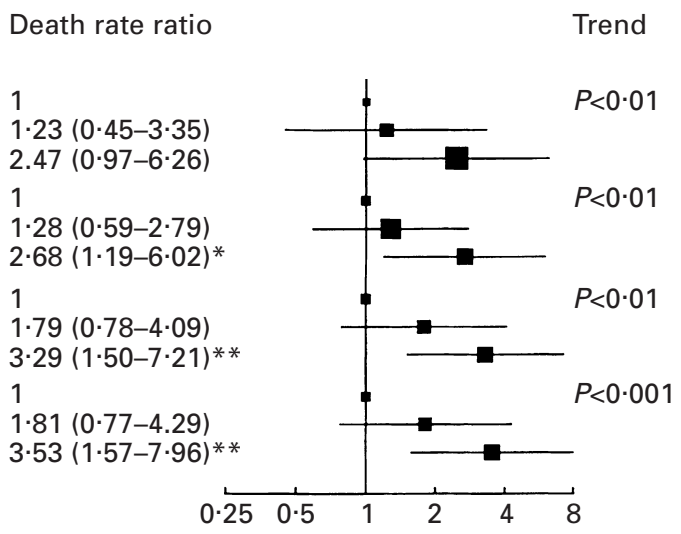

Fig. 5. Analysis of data from the Oxford Vegetarian study. Death rate ratios for IHD by dietary factor, among subjects with no evidence of preexisting disease at the time of recruitment, adjusted for age, sex, smoking and social class. Values are shown with $95 \% \mathrm{Cl}$ represented by horizontal bars; the area of each square is proportional to the number of deaths in that group. Death rate ratios were significantly different from those for the reference group: ${ }^{\star} P<0 \cdot 05,{ }^{* \star} P<0 \cdot 01$. (Adapted from Mann et al. 1997.)

vegetarians than in non-vegetarians; this was not statistically significant (death rate ratio $0.95(95 \%$ CI $0.82,1 \cdot 11)$ ), but this is compatible with the $24 \%$ reduction in mortality from IHD which was responsible for $27 \%$ of all deaths.

\section{Morbidity}

Relatively little information is available concerning morbidity in vegetarians. There is some evidence that vegetarians may have a lower incidence of constipation (Burkitt et al. 1972), diabetes (Snowdon \& Phillips, 1975), diverticular disease of the colon (Gear et al. 1979), gallstones (Pixley et al. 1985), hypertension (Beilin, 1993) and emergency appendicectomy (Appleby et al. 1995).

\section{Conclusion}

Compared with non-vegetarians, Western vegetarians have a lower BMI (by about $1 \mathrm{~kg} / \mathrm{m}^{2}$ ), a lower plasma cholesterol concentration (by about $0.5 \mathrm{mmol} / \mathrm{l}$ ), and a lower mortality from IHD (by about $25 \%$ ). They may also have a lower risk for some other diseases such as diverticular disease, gallstones and appendicitis. No differences in mortality from common cancers have been established. There is no evidence of adverse effects on mortality. Much more information is needed, particularly on other causes of death, osteoporosis, and long-term health in vegans. The evidence available suggests that widespread adoption of a vegetarian diet could prevent approximately 40000 deaths from IHD in Britain each year.

\section{References}

Appleby P, Thorogood M, McPherson K \& Mann J (1995) Emergency appendicectomy and meat consumption in the UK. Journal of Epidemiology and Community Health 49, 594-596.

Appleby PN, Thorogood M, Mann JI \& Key TJ (1998) Low body mass index in non-meat eaters: the possible roles of animal fat, dietary fibre and alcohol. International Journal of Obesity 22, 454-460.

Beilin LJ (1993) Vegetarian diets, alcohol consumption, and hypertension. Annals of the New York Academy of Sciences 676, 83-91.

Burkitt DP, Walker ARP \& Painter NS (1972) Effect of dietary fibre on stools and transit-times, and its role in the causation of disease. Lancet ii, 1408-1412.

Burr ML \& Butland BK (1988) Heart disease in British vegetarians. American Journal of Clinical Nutrition 48, 830-832.

Chang-Claude J, Frentzel-Beyme R \& Eilber U (1992) Mortality pattern of German vegetarians after 11 years of follow-up. Epidemiology 3, 395-401.

Department of Health (1992) The Health of the Nation: A Strategy for Health in England. London: H.M. Stationery Office.

Dwyer JT (1988) Health aspects of vegetarian diets. American Journal of Clinical Nutrition 48, 712-738.

Dwyer JT (1991) Nutritional consequences of vegetarianism. Annual Review of Nutrition 11, 61-91.

Fraser GE, Sabaté J, Beeson WL \& Strahan TM (1992) A possible protective effect of nut consumption on risk of coronary heart disease. Archives of Internal Medicine 152, 1416-1424.

Gear JSS, Ware A, Fursdon P, Mann JI, Nolan DJ, Brodribb AJM \& Vessey MP (1979) Symptomless diverticular disease and intake of dietary fibre. Lancet $\mathbf{i}, 511-514$.

Key T \& Davey G (1996) Prevalence of obesity is low in people who do not eat meat. British Medical Journal 313, 816-817.

Key TJ, Fraser GE, Thorogood M, Appleby PN, Beral V, Reeves G, Burr ML, Chang-Claude J, Frentzel-Beyme R, Kuzma JW, Mann J \& McPherson K (1998) Mortality in vegetarians and nonvegetarians: a collaborative analysis of 8300 deaths among 76,000 men and women in five prospective studies. Public Health Nutrition 1, 33-41.

Mann JI, Appleby PN, Key TJ \& Thorogood M (1997) Dietary determinants of ischaemic heart disease in health conscious individuals. Heart 78, 450-455.

Pixley F, Wilson D, McPherson K \& Mann J (1985) Effect of vegetarianism on development of gallstones in women. British Medical Journal 291, 11-12.

Sanders TAB \& Reddy S (1994) Nutritional implications of a meatless diet. Proceedings of the Nutrition Society 53, 297-307. 
Snowdon DA \& Phillips RL (1985) Does a vegetarian diet reduce the occurrence of diabetes? American Journal of Public Health 75, 507-512.

Snowdon DA, Phillips RL \& Fraser GE (1984) Meat consumption and fatal ischemic heart disease. Preventive Medicine 13, 490500.

Thorogood M (1995) The epidemiology of vegetarianism and health. Nutrition Research Reviews 8, 179-192.
Thorogood M, Carter R, Benfield L, McPherson K \& Mann JI (1987) Plasma lipids and lipoprotein cholesterol concentrations in people with different diets in Britain. British Medical Journal 295, 351-353.

Thorogood M, Mann J, Appleby P \& McPherson K (1994) Risk of death from cancer and ischaemic heart disease in meat and nonmeat eaters. British Medical Journal 308, 1667-1671. 
https://doi.org/10.1017/S0029665199000373 Published online by Cambridge University Press 